\section{Antagonism by Indomethacin of Diuretic Response to Calcitonin in Man}

The diuretic effects of porcine and human calcitonin in animals and $\operatorname{man}^{1}$ are associated with renal vasodilatation. ${ }^{2}$ The hormone itself may not be directly responsible for these effects, however, and since intravenous calcitonin causes increased gastrointestinal activity and flushing in man, prostaglandins (particularly $E_{2}$ and $F_{2 a}$ ) may act as intermediaries. ${ }^{3}$ If so, the prostaglandin synthetase inhibitor, indomethacin, might modify this response.

\section{Methods and Results}

Seven healthy men, aged 21-30 years (mean 24), with normal renal function were studied. After fasting overnight they emptied their bladders and drank $200 \mathrm{ml}$ water. Urine samples were then collected over four consecutive hourly periods. After each period they drank water equivalent in amount to the urine passed to maintain a constant state of hydration. After obtaining the first (baseline) collection $0.2 \mathrm{mg}$ human calcitonin (CIBA) in $2.0 \mathrm{ml}$ normal saline was injected intravenously over one minute. In four men blood was taken from an intravenous cannula for serial plasma cyclic adenosine monophosphate (AMP) estimations during the first hour after calcitonin. This procedure was repeated in all seven men after seven days of indomethacin treatment (25 mg four times daily). Urine volumes were measured and aliquots frozen at $-20^{\circ} \mathrm{C}$ until analysis. Sodium and potassium concentrations were estimated on all samples by standard autoanalyser techniques. Plasma and urinary cyclic AMP were measured using a saturation assay. ${ }^{4}$

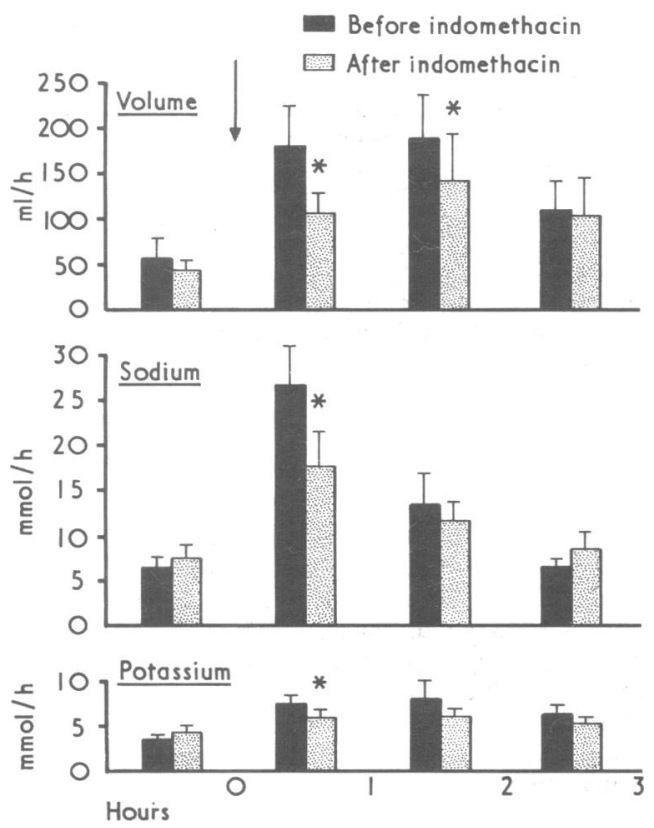

Mean effect ( $t$ S.E. of mean) of $0.2 \mathrm{mg}$ human calcitonin given intravenously to seven men before and after indomethacin $25 \mathrm{mg}$ six hourly for seven days. Calcitonin injections at time 0 on both occasions.

*Significantly different from control value $(P<0.05$, paired $t$ test).
All subjects had sodium and water diureses after intravenous calcitonin, but the increase in urinary potassium output was less pronounced. Indomethacin significantly reduced urinary sodium and potassium output in the first hour after calcitonin and urine volume during the first two hours (see fig). One man received a further injection of calcitonin four weeks after discontinuation of indomethacin. His diuretic response was similar to that obtained before indomethacin. All subjects had fewer gastrointestinal effects and reduced flushing after indomethacin. Mean urinary cyclic AMP rose in the first hour after calcitonin, and this increase was less apparent, but not significantly so, after indomethacin. Plasma cyclic AMP levels did not change significantly or consistently with intravenous calcitonin either before or after indomethacin.

\section{Discussion}

Our results show that oral indomethacin can significantly reduce the diuresis and natriuresis induced by intravenous calcitonin. The response after indomethacin was also the response to the second injection of calcitonin, but acquired resistance to the renal action of calcitonin was unlikely to have caused the diminished natriuresis observed.

Urinary and plasma cyclic AMP were measured for two reasons. Firstly, a hypocalcaemic response to calcitonin might induce a secondary increase in parathyroid hormone output. This hormone's action on the kidney is associated with an increase in urinary cyclic AMP. Secondly, prostaglandin-mediated responses in some organs are associated with increased activity of the adenyl cyclase system, and urinary or plasma cyclic AMP might increase for this reason. In our experiments, however, neither urinary nor plasma cyclic AMP content changed significantly. Though our results suggest that indomethacin antagonizes the renal action of calcitonin, the nature of this effect is not clear and might equally well represent competitive or non-competitive pharmacological antagonism, a pharmacokinetic interaction, or physiological competition unrelated to a common mediating pathway. The role of prostaglandins in the local regulation of renal blood flow and in tubular sodium reabsorption seems to be established, ${ }^{5}$ and therefore indomethacin, by inhibiting renal prostaglandin synthetase activity, may block calcitonin-induced stimulation of prostaglandin synthesis and release. Our observations support the concept that prostaglandins are involved in renal mechanisms controlling sodium and water balance in man, and that exogenous calcitonin may mediate its renal effects through this system.

We thank all our volunteers, Mrs. Jeanette Cunningham and Mr. Glyn Holbrow for technical help, Dr. D. Burley (CIBA Laboratories) for supplies of synthetic calcitonin, and Mrs. I. M. Henderson, who typed the paper.

1 Ardaillou, R., et al., Comptes Rendus Hebdomadaires des Séances de l'Académie des Sciences, 1967, 264D, 3037.

2 Edwards, I. R., and Smith, A. J., Clinical Endocrinology, 1972, 1, 337

3 Lee, J. A., Archives of Internal Medicine, 1974, 133, 56.

${ }^{4}$ Brown, B. L., et al., Biochemical fournal, 1971, 121, 561.

${ }^{5}$ Lonigro, A. J., et al., Circulation Research, 1973, 32, 7120.

Section of Therapeutics, Academic Division of Medicine, University of Sheffield

D. B. BARNETT, M.B., M.R.C.P., Merck, Sharpe and Dohme International Research Fellow in Clinical Pharmacology (Now Division of Clinical Pharmacology, Moffitt Hospital, San Francisco)

I. R. EDWARDS, M.B., M.R.C.P., Lecturer in Pharmacology and Therapeutics

A. J. SMI'TH, D.M., F.R.C.P., Associate in Medicine 